\title{
Research and Rehabilitation: The Conflict of Scientific and Treatment Roles in Corrections*
}

\author{
JeROME RaBow \\ Pre-doctoral Fellow, Social Psychology, University of Michigan \\ B.A., Brooklyn College, 1955; M.A. (Sociology), Columbia University, 1962
}

The general dysfunctions resulting from the separation of practitioners and researchers, in the field of corrections are described. The means by which both groups fail to contribute to the development of a scientific penology as a result of different evaluations of a relatively similar frame of reference is explored. The common elements in their respective frames of reference, and the requirements of a scientific penology, suggests the need for closer working relationships between practitioner and researcher. A general model for cualuation in corrections is presented and the steps by which integrative efforts can be attempted are explored on the basis of the model.

$T$ IIE contribution any rehabilitation program can make to a field of knowledge is determined not by impressionistic evidence that can be gathered in favor of the program but by scientifically adequate evidence that places the program within the context of a sound research design. By this means a program can be evaluated rigorously in comparison with other treatment approaches. Nevertheless, the urgent need for sound research in corrections has, as yet, not been met on any wide scale by social scientists. As Ohlin has pointed out "the creation of a realistic design for evaluative research would unquestionably do more to speed the development of a science of penology than any other single contribution."1

* This article was written while the author was a Research Associate at the Provo Experiment in Delinquency Rehabilitation, Brigham Young University, Provo Utah. Research funds for the Experiment were made available by the Ford Foundation to whom gratitude is expressed. The author is indebted to LaMar T. Empey, Director of the program for his active support and stimulation in the formulation of the problem discussed herein.

'Lloyd E. Ohlin, Sociology and the Field of Corrections, New York: Russell Sage Foundation, 1956, p. 52.
Although some factors, such as the difficulties involved in setting up controlled experiments in correctional facilities, are discussed in the literature, ${ }^{2}$ some of the main reasons for the paucity of sound research are unarticulated. One important aspect of this lack of articulation is not intrinsic to the difficulties associated with setting up and clescribing well designed programs, but is inherent in an ideological gulf separating those persons responsible for treatment from those responsible for treatment evaluation.

This gulf, which has been described as an "age old split," 3 has created many dif-

"Joseph Zubin, "Design for the Evaluation of Therapy," Psjchiatric Treatment, Baltimore: The Williams and Wilkins Co., 1953, XXXI, pp. 10-15; Eli A. Rubinstein and Morris B. Parloff, eds., Rescarch in Psychotherapy, Washington, D. C.: American Psychological Association, 1959; Elizabeth Herzog, "Some Guide Lines for Evaluative Research," Washington, D.C.: U.S. Department of Health, Education, and Welfare, 1959, pp. 64-71.

"Benjamin Kotkov, Chapter 19, "Research," in The Fields of Group Psychothcrapy, ed. by S. R. Slavson, New York: International Universities Press, Inc., pp. 316-317. Kotkov describes experimental contributions without emphasizing the dysfunctions of the division. Paul E. Mechl in Clinical versus Statistical Predic- 
ficulties in corrections. In certain instances, historical arguments between professionals in the behavioral sciences have proved to be important for scientific advancement; members of opposing groups were willing or pressured to reexamine and revise concepts, assumptions and premises, and occasionally procedures. The arguments between treatment and research groups in corrections have not, as yet, proved especially fruitful.

While both groups agree that knowledge about treatment is important, in practice, their disagreements seem to belie their common orientation. Perhaps this is because the disagreements are inherent in the present division of labor with respect to treatment. The treatment group focuses on practical problems of a "here and now" nature, while researchers are more concerned with the abstract problems of setting up research so that there might be some ultimate evaluation.

The resulting differences between the two have been akin to political debates in which the debaters tend not only to utilize different facts to support their points of view, but disagree with the interpretation of the facts which they have in common. Thus, typically, the clinician says, "Recidivism is not a good criterion of success because it overlooks those who are 'better adjusted' and whose offenses, therefore, are "less serious'." The researcher counters with, "You may be right, but what empirical evidence do you have that the success rate might not have been just as high for those who received no treatment whatsoever or perhaps received a different kind of treatment"?

This paper will focus on some of the sources of conflict between scientific and treatment personnel as well as the dysfunctions created by those conflicts for the

tion, presents a precise but detailed examination of the more general conflict existing between clinicians and actuarilists, University of Minnesota Press, Minneapolis, 1959.

1 Donald R. Cressey, "The Nature and Effectiveness of Correctional Techniques," Law and Contemporary Problems, Vol. 23 (Autumn, 1958), pp. 754-771. field of corrections. Specifically the researcher-evaluator role and the cliniciantherapeutic role are under examination. It should, however, become clear to the reader that the description of the problems described in this particular case study and the suggested solutions have a much broader application to the difficulties generated by contact of the practitioner, be he teacher, social worker or administrator, with the researcher. The obvious similarities to other areas will be ignored and the focus will be upon the conflicts as they manifest themselves in the corrections field.

\section{Historical Perspective for the Separation}

This ideological separation between clinician and researcher is part of the age old split between men of socially planned action and men whose lives are devoted to the abstract problem of cultivating and formulating knowledge. The men of action have undertaken rehabilitation, educational training and settlement house work, all with the very practical problems of having to do something. Traditionally their idea has been that the effectiveness of the methods they used could be based upon common sense and testimony as to their efficacy.

This kind of humanitarian approach is obvious in many American correctional practices today. Any techniques which make the offender's life more comfortable or his surroundings more home-like are embraced and considered helpful. They are considered beneficial because they seek both to reduce deprivations resulting from impoverishment or incarceration and to produce the warm emotional environment of which many offenders were supposedly deprived in earlier years.

But, in addition to humanistic values, such treatment approaches also include many middle class values, ${ }^{6}$ some residues

\footnotetext{
- Robert K. Merton, Social Theory and Social Structure, Glencoe: The Free Press, 1957, p. 209.

- Donald R. Cressey, "Limitations on Organization of Treatment in the Modern Prison," Theorctical Studies in Social Organization of
} 
of a punishment philosophy and an admixture of Freudian Psychology and social science information. From a researcher's point of view, this amalgam is an evaluative nightmare. The potpourri of humanistic and middle class values which form the foundations for many practices, because they have been viewed as absolutes, have not been subjected to evaluation. In a similar way many clinical practices are viewed as an art in which any evaluation must be intuitive and subjective $^{7}$ rather than empirical and objective.

As a consequence, treatment practices are accepted a priori and the men who hold them tend to proceed with unbounded faith in what they are doing, apparently feeling that any problems are due to a failure to apply what is known rather than to evaluate that which is in progress. They are more concerned with pointing out the need for "professional treatment" than in defining the precise way in which such treatment is applied or is successful in changing people.

On the other hand, the traditional position of the evaluator might best be compared to that of an "unattached intellectual"8_an individual who has little commitment to the system he is examining: economic, emotional, or otherwise.

The researcher can continue to be adamant in abiding by his suggestions and findings since he is not intimately involved in translating them into action. Consequently he often fails to recognize the multifarious problems which must be borne by administrators and clinicians who are responsible for treatment. ${ }^{2}$

The traditional arguments and counter-

the Prison, New York: Social Science Research Council (March, 1960), pp. 92-93.

'Reik contends that most insights and understanding in psychoanalysis spring from the therapist's and the patient's unconscious. Any attempts to categorize treatment in a "systematic, orderly, consistent" manner will result in drivel. Theodor Reik, Listening With the Third Ear, New York: Grove Press, Inc., 1948, pp. 440-441.

- Merton, op. cit., p. 211.

Ibid., pp. 218-219. arguments by both treaters and researchers have been latently functional in that they have served as ideologies which have given each group a sense of identity, meaning, and purpose. But the manifest functions for which each group supposedly exists, i.e., to improve and apply treatment successfully, has been lost in the effort of each to maintain its own vested interest. Any possibilities for treatment to be viewed as a dynamic and creative phenomenon has been stifled because latent functions have become ascendant. But just as the question of federal aid to education may not be effectively resolved by the clash between vested interests, the question of improved treatment likewise may not be effectively resolved on the merits of latent arguments designed to protect existing patterns.

Instead, the dysfunctions of these latent positions must be demonstrated, any virtues residing in them must be brought out, and new alternatives explored which might make possible an inventive approuch to treatment. The remainder of the paper is devoted to this task.

\section{Some Basic Questions and a Researci Model}

Scientifically selected treatment and control groups are imperative for any realistic evaluation of treatment. Yet, only rarely have such groups been systematically compared. But to add complexity to an already difficult problem, it should be noted that a comparison of groups, whether on the basis of recidivism rates, personality tests, or other characteristics, is only one dimension of evaluation. In the absence of supporting information, significant statistical differences among groups do not necessarily justify attributing these differences to one treatment method or the other. In many cases differences might not be a direct function of treatment, but due to the effect of other variables which the statistical comparison does not reveal.

Before differences can be attributed to the utilization of a particular treatment 
approach, evaluation would have to be seen as occurring in a series of stages in which answers to several important questions were available. The following are possible stages.

Stage $I$ is concerned with the population of offenders from which treatment and control groups will be selected. A.sswers for such questions as the following are needed:

1. How is the population of offenders from which groups will be selected defined with respect to age, record of offenses, geographical location, or any social or personality characteristics though to be important?

2. How is selection carried out in order to eliminate bias-by random means or some matching process?

3. When, and by whom, is selection carried out? What are the mechanics?

4. What steps are taken to demonstrate the lack of bias in selection?

Stage II is concerned with the treatment process and the need to understand what is involved in it:

1. What is the theory of causation upon which treatment is proceeding?

2. What is the intervention strategy utilized in treatment by which the causation variables will be modified?

3. Can a logical relationship between causation variables and intervention strategy be demonstrated?

4. Can it be demonstrated that the treater is fulfilling role requirements specified by the intervention strategy?

5. Assuming that treatment role requirements are being fulfilled, can it be demonstrated that variables cited in the theory of causation are being modified?

6. How shall any change in variables be measured?

Stage III involves the actual comparisons of groups subsequent to treatment and is concerned with such questions as:

1. What are the goals of treatment; that is, how shall success be defined-in terms of recidivism, attitudinal change, new social relationships, personality modification?

2. How is measurement of these characteristics carried out?

3. Over what period of time are comparisons to continue?

4. How is cooperation of subjects obtained?

\section{Other Variables}

In addition to the variables in each of these stages, there are others-race, class, marital status, job status, etc.-which can also affect treatment results. Because these variables are not a direct function of treatment, efforts must be taken to control them or they can result in misleading and unexplained differences.

Figure I sums up graphically the stages just described. It might be viewed as a research model highlighting the need for a systematic integration of research and treatment.

The necessity of having information for each stage of evaluation becomes manifest when one considers a few of the ways in which it can affect the statistical comparisons. Suppose, for example, a statistical comparison of treatment and control groups reveals no differences among them. Without further knowledge it is difficult to assess such findings. But if a careful analysis of Stage II (causation theory and intervention techniques) indicates that the causation variables thought most important were successfully altered, then it is possible that methods for selecting the groups were biased (Stage I) or that treatment has been concentrated on the wrong variables. In either case, one has better information on where to search for answers.

On the other hand, if the statistical comparison of groups revealed that there were significant differences in favor of the treatment group, and that causation variables were successfully altered, then it would be more reasonable to assunie that causation and intervention theory had an important effect on rehabilitationproviding, of course, that other important 


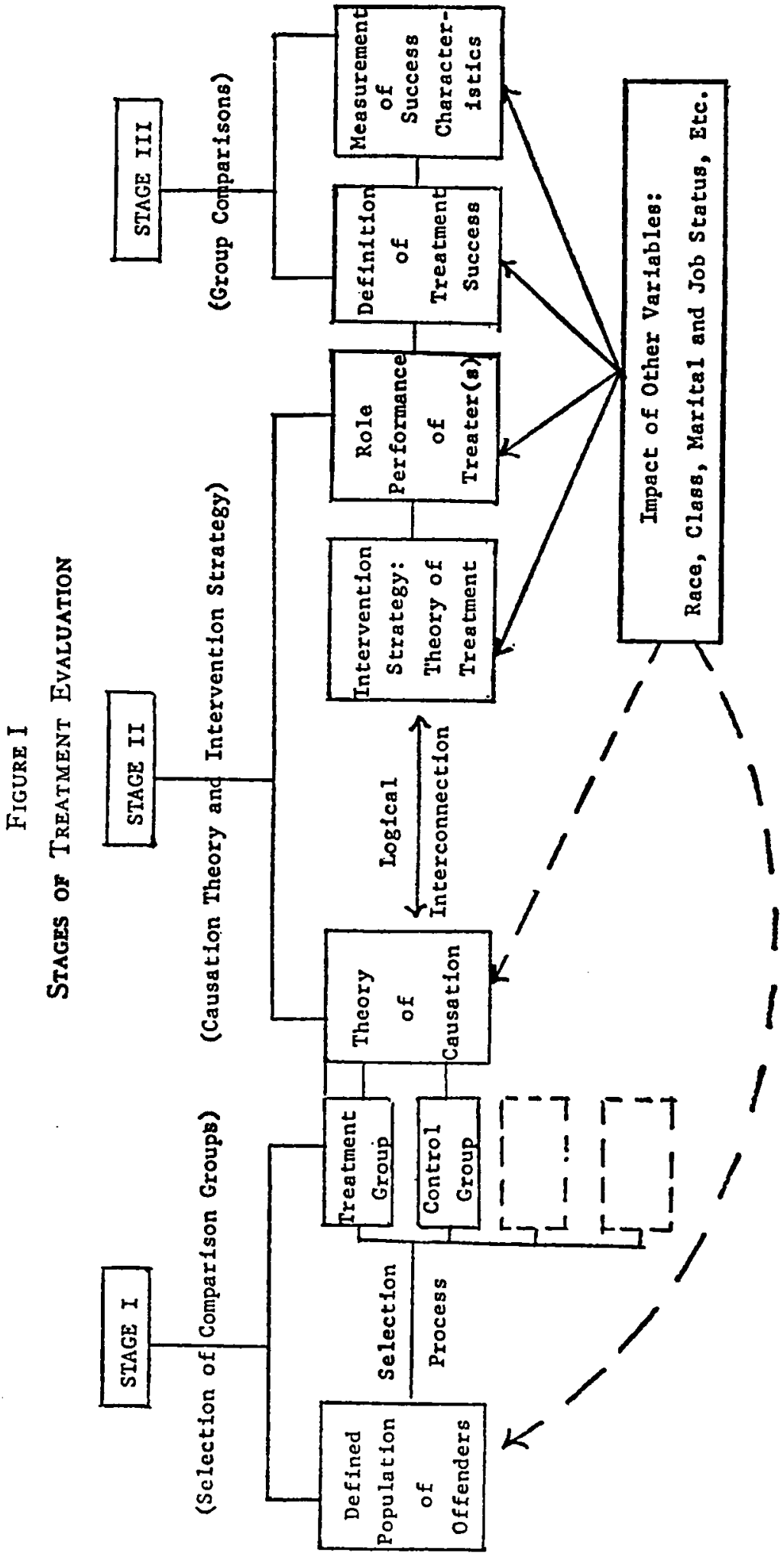


variables such as race, marital status, etc., were controlled.

Finally, in a more complex way, suppose the analysis revealed that, although significant statistical differences occurred between groups, important causation variables were not actually altered. In attempting to discover what had caused the differences, one would have to investigate several problems: Was there bias in the method of selecting treatment and control groups (Stage I) ? Is causation theory correct (Stage II)? Was the comparison carried out over a long enough period of time (Stage III)? Were outside variables sufficiently controlled?

Since answers to these questions form the foundation for knowledge about treatment programs, any examinations of the arguments between clinician and researcher should be analyzed in the light of them. In this way it might be possible to pinpoint present difficulties. It should be kept in mind, however, that this paper is not concerned with all of the difficulties which inhibit effective treatment and evaluation. It focuses instead upon the manner in which the bifurcation of treatment and research roles permits treatment to proceed without scientific validation.

\section{Dysfunctions Perpetuated by the Treatment Group}

The Dearth of Research on

\section{Treatment Techniques}

Most professionals in corrections, or otherwise, seem to feel that some evaluation of treatment methods is warranted, although, as Goode points out, the few evaluations of such techniques as psychotherapy that have been made do not meet "minimum canons of research design."10 But most clinicians are either unwilling or unaware of the need to subject themselves and their techniques to the various stages of evaluation by which

\footnotetext{
${ }^{20}$ William J. Goode, "The Profession: Reports and Opinions," American Sociological Review, 25 (Dec., 1960), p. 912.
}

statistical comparisons can be made meaningiul.

One of the greatest obstructions is the tendency for existing treatment theories and methods to be accepted virtually on an a priori basis. For example, many people have assumed that since "the effectiveness of psychotherapy has long since been established,"11 it can be applied effectively to the treatment of criminals. Yet, neither assumption is empirically validated. ${ }^{12}$

The psychotherapist's role has seldom, if ever, been examined since many clinicians feel that research on it is superfluous. In their opinion all of the necessary rules of conduct in therapy are known. ${ }^{13}$ Yet, most descriptions of the clinical role are derived from different schools of thought and are generalized rather than specific in nature. ${ }^{14}$ Thus, the

"Rubinstein and Parloff, op. cit., pp. 278. These authors do not assume the effectiveness of psychotherapy but mention those who do.

"Hans J. Eysenck, "The Effects of Psychotherapy: An Evaluation," Journal of Consulting Psychology, 16 (1952), pp. 319-324; Karl R. Schuessler and Donald R. Cressey, "Personality Characteristics of Criminals," The American Journal of Sociology, 55 (March, 1950), pp. 476-484; LaMay Adamson and $H$. Warren Dunham, "Clinical Treatment of Male Delinquents: A Case Study in Effort and Result," American Sociological Revicze, 21 (June 1956), p. 320. Davidson gocs so far as to suggest that the "psychiatric" approach does not work with delinquents. Henry A. Davidson, "The Semantics of Delinquency," The Welfare Reporter, New Jersey State Department of Institutes and Agencies, XI (July, 1960), p. 135.

${ }^{2}$ Hans-Lukas Tueber and Edwin Powers, "Evaluating Therapy in a Delinquency Prevention Program," Psychiatric Treatment, Baltimore: The Williams and Wilkins Co., XXXI (1953), p. 145.

"Gisela Konopka, "The Role of the Social Group Worker in the Psychiatric Setting," American Journal of Orthopsychiatry, 22 (1952), pp. 176-185; Rudolf Kaldeck, "Group Psychotherapy by Nurses and Attendants," Diseases of the Nervous System, 1950-1951, 12 (February, 1951), pp. 138-142; Margaret Hagan and Marion Kenworthy, 'The Use of Psychodrama as A Training Device for Professional Group Workers in the Field of Human Relations," Group Psychotherapy, IV (AprilAugust, 1951-1952), pp. 23-40; Henrietta T. 
assumption that all therapists follow a recognized and shared treatment role is highly questionable and merits examination.

If the treatment role remains unarticulated and unevaluated, results such as those obtained in the Cambridge-Sommerville Study will continue to occur. ${ }^{15}$ In that project, statistical comparisons revealed that the number of offenses for the treatment group was greater than those for the control group, while counselors felt that therapy was effective with two-thirds of the treatment group. This discrepancy highlights the importance of having information on the treatment procedure (Stage II). Counselors in that study had the opportunity before they began treatment to define the "helping" role, to indicate their goals, and how they expected to achieve these goals. However, because they failed to do so, it is impossible to know what led to the results obtained: whether they were due to the theory of treatment utilized, the failure of counselors to fulfill roles derived from treatment theory, or to other variables. Thus, treatment, as the independent variable, cannot be taken for granted. It must be subjected to scrutiny.

Likewise, the way in which personality

Glatzer and Helen E. Durkin, "The Role of the Therapist in Group Relations Therapy," The Nervous Child, 4 (April, 1945), pp. 243251 ; S. H. Foulkes and E. J. Anthony, Group Psychotherapy: The Psycho-Analytic Approach, Penguin Books (1957); Rudolph Ekstein and Robert S. Wallerstein, The Teaching and Learning of Psychotherapy, New York: Basic Books, Inc., 1958, passim; Robert G. Hinkley and Lydia Hermann, Group Treatment in Psychotherapy: $A$ Report of Experience, Minneapolis: Universicy of Minnesota Press (1951), passim. One recent exception is a publication by Henry L. Lennard and Arnold Bernstein, The Anatomy of Psychotherapy, New York: Columbia University Press, 1960, passim.

4 Tueber and Powers, "Evaluating Therapy in A Delinquency Prevention Program," op. cit., pp. 138-146. See also Edwin Powers and Helen Witmer, An Experiment in the Prevention of Delinquency: The Cambridge-Somerville Youth Study, New York: Columbia University Press (1951). disorders might relate to criminality have not been empirically demonstrated. ${ }^{16}$ Yet, treatment methods based upon the idea of their importance have flourished. Until it can be shown that there is a clear relationship between any transformed personality characteristic and a lower recidivism rate, the theory must be subject to question. At present we have neither the evidence to accept or reject it.

\section{The Treatment Potpourri}

Another treatment problem contributing to research difficulties lies in the extent to which correctional facilities, as part of their general treatment programs, include a great variety of treatment practices. Each of these practices might be viewed as a separate treatment technique and evaluated as such. Yet, the entire host of procedures is also often considered as a single entity for which evaluation is asked. For example, Gersten describes how interview group therapy, directive and nondirective therapy, handicrafts, films, and psychodrama were employed in a single treatment program. Although the program was judged successful by several criteria, it is difficult, if not impossible, to tell which specific techniques of the program contributed to its success. $^{17}$

Before legitimate examination can be made of any total treatment program, steps must be taken by which to assess the merits of specific treatment practices in the total picture. Obviously this is a difficult task, but there are at least two principles whose adoption might maximize a solution to the conundrum of relative effectiveness.

First, treatment personnel might pay

\footnotetext{
${ }^{4}$ Schuessler and Cressey, op. cit.; see also Henry D. McKay, "Differential Association and Crime Prevention: Problems of Utilization," paper read at the annual meetings of the American Sociological Society, Chicago, September 2-5, 1959.

${ }^{27}$ Charles Gersten, "An Experimental Evaluation of Group Therapy for Juvenile Delinquents," International Journal of Group Psychotheropy, I (1951), pp. 18-33, pp. 318-331.
} 
greater attention to the need for establishing logical integration among the treatment techniques they utilized. The ideal would be to devise a treatment program around specific and logically integrated theories of causation and intervention. Only those techniques shown to have relevance would be included. A potpourri of unrelated activities could, and probably woùld, set up conflicting goals. For example, if one theorized that delinquency is primarily a peer group phenomenon, he might then want to test this theory by concentrating on techniques designed to change peer relationships. Attempts on his part to utilize individualized as well as group techniques, each of which is derivable from different intervention theories, could easily destroy his efforts to make a systematic evaluation of his causation and treatment theories.

The second principle would involve the integration into any program, means by which specific segments of that total program could be examined and evaluated with respect to their contribution to successful rehabilitation. Later evaluation of the total program as a single entity might then have greater meaning. The corollary, and ideal result, would be the development of a self-correcting system capable of discarding those techniques which are inadequate and promoting those which are of value.

\section{Professional Canonization}

Treatment personnel who have the practical problem of dealing daily with inmates cannot be expected, any more than the general medical practitioner, to create many new and revolutionary approaches to treatment. Nevertheless, the efforts of some schools of treatment to maintain their vested interests go beyond the necessity to train treatment personnel. Their efforts are dysfunctional for a scientific penology because they place an undue emphasis on the canonization of new inductees at the expense of determining the validity of their own treatment methods.
Current training procedures seldom emphasize skepticism and creativity as an approach to treatment, but instead concentrate upon the steps necessary for certification. Concern over the latent function of maintaining professional stature and prestige tends to outweigh the manifest need for improved treatment techniques. As a consequence, the treater role is circumscribed with a whole series of prerequisites which can be obtained only under the observation and supervision of those already canonized. ${ }^{18}$

It is difficult to take exception to the idea that treatment personnel should be well trained. But all too often the techniques, and the process of learning them, become ends in themselves. The resulting effect on the trainee is to provide him with an efficient set of blinders-blinders which enable him to misperceive or ignore programs whose rehabilitative efforts do not include techniques consistent with the standards which he has been taught to accept.

\section{The Anxiety of Evaluation}

The canonization of treatment personnel, and the institutionalization of treatment techniques, introduce problems of evaluation which are unrelated to the tremendous methodological difficulties in-

\footnotetext{
" These prerequisites emphasize personality characteristics as well as training. In some. schools, personality requirements include: the therapist's ability to deal effectively with his own anxieties; to be comfortable with certain types of emotional behavior; (Morris B. Parloff, "Some Factors Affecting the Quality of Therapeutic Relationships," in Group Psychotherapy, ed. by William F. Hill, Utah State Hospital, Provo, 1961, pp. 179-187) and to have come from a background with a wide variety of personal experiences. (S. R. Slavson, "Qualifications in Training of Group Therapists," Mcntal Hygiene, XXXI (1947), pp. 386-391; Gisela Konopka, "Group Therapy; Knowledge and Skills of the Group Therapist," American Journal of Ortho-Psychiatry, XIX (1949), pp. 56-60.) Training includes observation, practiced application, supervision, and often stresses individual therapy for the candidate. Aichhorn stressed the latter point in 1925. August Aichhorn, Wayuard Youth, New York: The Viking Press (1935), p. 9.
} 
volved. Besides clinicians, administrators and board members concentrate more upon lending credence to already accepted methods than to an objective, unbiased appraisal of the techniques used. This approach again is analogous to the debater who seeks mainly for evidence to support his previously accepted proposition rather than to the scientist who refrains from making any conclusion until he examines both sides of a question. The debater presents only those data which support his viewpoint and discards the remainder. The scientist must draw his conclusion from the total mass of data.

Because many people are committed to particular treatment approaches, any objective evaluation is viewed with anxiety. As a result, the evidence presented in favor of a program by treaters is usually anecdotal in which striking examples of success are illustrated, but in which failures are rarely mentioned, or, if mentioned, are explained with a series of complex rationalizations. Thus, we may hear: "The technique is effective enough, but it is not designed for this particular individual (failure)," or, "This study doesn't really invalidate our approach. It just points up the need for a much longer experimental study," or, "Our program may be a statistical failure, but how can you judge a program by its failures! If one man was saved from a life of crime, then I consider it worthwhile."18

By hiding behind such rationalizations those responsible for treatment are seldom required to define their goals or to attempt to relate them systematically to their intervention techniques. Consequently, treatment may often pursue ends which may not be directly associated with lawbreaking, e.g., personality adjustment, educational achievements, or the learning of handicraft or athletic skills. Perhaps this is what occurred in the Cambridge-Sommerville Study when the treatment group seemed to benefit in ways unrelated to lawbreaking. The recidivism

\footnotetext{
"Cressey, "The Nature and Effectiveness of Correctional Techniques," op. cit.
}

rates of offenders were not appreciably changed, but certain qualitative adjustment differences occurred.

If greater efforts were expended in the direction of carefully defining treatment goals and in attempting to show how they relate to lawbreaking, research might then be able to indicate: (1) whether important goals were actually realized; and (2) whether, if they were realized, they helped to lower the recidivism rate. But, again, a systematic articulation and examination of goals depends upon the extent to which treatment is a function of logically integrated causation and intervention strategy. A conglomeration of unrelated activities is functional in maintaining vested interests because there is something in it for everyone. But it also makes a careful definition of goals difficult and effective evaluation impossible.

\section{Dysfunctions Perpetuated by the RESEARCHER}

Research personnel have also perpetuated dysfunctions with regard to effective treatment evaluation. The following are some of the more important ways in which they have done this.

\section{The Emphasis on "Pure" Rescarch}

It has become traditional among many social scientists to question the scientific objectivity of any individual who becomes involved in an action program. ${ }^{20}$ This tration is not without some validity. William Graham Sumner pointed out, early in the

\footnotetext{
- See the discussion of Max Weber by Harry E. Barnes and Howard Becker, Social Thought From Lore to Science, New York; D. C. Heath \& Co., 1938, II, pp. 896-898; and Donald R. Cressey, "Changing Criminals: The Application of the Theory of Differential Association," The Amcrican Journal of Sociology, 61, (July, $1955)$, p. 116, who says "... Sociology is essentially a research discipline..." For opinions to the contrary sce Robert S. Lynd, Knowlcdge For What, Princeton University Press, 1939; and Edward A. Shils, "Social Inquiry and the Autonomy of the Individual," in The Human Mcaning of the Social Sciences, ed. by Daniel Lerner, New York: Meridian Books, Inc., 1959.
} 
development of American sociology, the difficulty of discussing and criticizing any social system of which one is an intimate part. $^{21}$

But this tradition is dysfunctional for scientific penology' in at least three ways: (1) It does not take into account advancements in such fields as Anthropology, Psychology, and Sociology, which give the modern social scientist considerable insight into social-psychological mechanisms and the relativity of any approach to treatment, (2) It separates the researcher from intimate contact with the subjects of his study, and, while he may have contributed to an understanding of the causes for delinquency, he is dependent upon the intuitive interpretations of the clinician for information regarding both the usefulness of his theory and its application in the treatment process, (3) It removes him from the process of planning and evaluating the early stages of any research project-that is, he is seldom involved in helping to integrate logically the intervention strategy with the theory of causation, with helping to define and examine the treatment role, and with defining treatment goal in such a way that they can be evaluated. Thus, he usually enters the picture late in the process in an attempt to evaluate a program that he knows relatively little about. His principal recourse is to make a statistical comparison of groups or to do post-mortem interviews with treaters and subjects. However, as suggested above, such techniques may be notoriously inadequate. ${ }^{22}$

In the absence of specific information about the treatment process, the researcher is incapable of determining the errors or strengths in the intervention strategy or errors or strengths in the way the strategy is applied. Consider the following example from the author's own experience.

William G. Sumner, Folkway's, Boston, 1907, pp. 97-98.

- See also Tueber, op. cit., p. 141, who discusses the weaknesses of interviewing with delinquents.
An offender, two months after release from the Provo Experiment in Delinquency Rehabilitation, ${ }^{23}$ burglarized a home with his younger brother and stole $\$ 380$. Yet, at the time of his release there was little question in anyone's mind that this boy would be a success. The therapist in charge of the boy's daily therapy group, as a part of the research evaluation, predicted that the boy would be a success. Likewise, the interviewer who gave him his release interview was impressed with his actuity and perceptiveness. He was able to verbalize well about the treatment system: The stages of development through which his group had gone, the importance of his own ability to help other boys and be holped in return, the changes in his friendship and familial relationships, and his feelings about himself. After he had gotten into trouble, however, a careful look at the treatment process was in order. Fortunately, some data were available.

The following is one cxample of the types of information that were revealed. One of the basic assumptions for treatment in the program was never utilized as a part of the boy's trcatment experience. This assumption involved anxiety and suggested that because most habitual delinquents are affectively and ideologically dedicated to the delinquent system, they must be made anxious about the ultimate utility of that system for them. Several things revealed, however, that this boy had never really been made uncomfortable in his entire stay in the program. It seemed likely that he had never been forced by a feeling of necessity to examine himself deeply or to evaluate realistically the implications of continued delinquent behavior. In summary, it appeared that the role of the therapist had not been adequately filled.

Such a finding does not, by itself, constitute a complete answer as to why the

- Lamar T. Empey and Jerome Rabow, "The Frovo Experiment in Delinquency Rehabilitation," Atncrican Sociological Reriew, 26 (Oct., 1961), pp. 679-696. 
boy failed. It does suggest, however, at least two important things: (1) that so long as the therapist does not perform consistently with the theory of intervention, treatment technique designed to test that theory will not be adequately examined; and (2) that if the program had relied solely on the therapist's subjective interpretation or upon the researcher's statistical analysis this and other factors contributing to an understanding of the boy's failure would have remained undetected. An emphasis on "pure" research at the expense of an intimate surveillanse of the treatment process leaves too many unanswerable questions.

\section{Inodequate Knowledge of Treatment for Predictive Purposes}

The greater portion of research in penology has concentrated upon "objective" variables-work reports, length of stay, job prospectus, etc.-as a means of measuring success or failure on parole. In terms of the ideological conflict between researcher and treater, this concentration is the counterpart of the treater's resistance to a rigorous evaluation of the treatment process per se. Although "objective" variables are important because of their impact on the offender, they can be seen, when viewed in terms of the theorical scheme mentioned earlier, as variables which impinge upon treatment but are not always a function of it. Therefore, predictions based upon them do not include any information on, or evaluation of, the very variables-i.e., those which are a direct function of some treatment technique, which, according to the treater, are most important in changing people. Consequently, most predictions are based on a segment of variables which affect the offender, not upon a total configuration. ${ }^{24}$

\footnotetext{
* The importance of having descriptive information on particular types of populations has been cited recently by Paul Mcehl and Edward Rosen. See "Antecedent Probability and the Efficiency of Psychometric Signs, Pattern or Cutting Scores," Psychological Bulletin, 1958, p. $199-211$.
}

Any prediction based upon the results of a particular treatment process can only follow a systematic articulation and understanding of that treatment process. But the researcher seems to have accepted the clinician's premise that therapy, like true art, consists of the "concealment of all of the signs and efforts of the art."2s

Treatment, the clinician asserts, in an ongoing process : It is a dynamic and subjective experience for everyone involved. How, therefore, can it be systematically codified and articulated? Furthermore, the relationship between counselor and counselee is a subtle but indispensable variable which is of value in and of itself. These delicate but important variables, he maintains, cannot be evaluated except intuitively. Consequently, any predictions based upon them must likewise be intuitive.

Apparently, it has been functional for the researcher to accept this point of view. But, as a result, he and the clinician have ended up using two different frames of reference in evaluating treatment. The researcher uses statistical data and "objective" variables which are not always shown to have a clear connection with the treatment process. And the clinician has utilized subjective interpretations based upon his feelings for what has occurred in therapy. By contrast, there are research findings in the behavioral sciences which suggest that if treatment techniques, per se, were productively analyzed, predictions could be based on them and "objective" variables as well. The two would constitute a larger body of empirical data from which to make predictions. For example, in addition to controlling such "objective" variables as marital status, job outlook, length of stay, etc., the total treatment setting might be examined as a social system in which participants develop and are guided by a shared set of values, norms, statusroles, and sanctions; the types of treatment interaction thought most productive could be defined and the actual behavior

\footnotetext{
Merton, op. cit., p. 14.
} 
during treatment sessions analyzed to see whether interaction conforms to these standards; or "stimulated recall" 26 might be conducted on subjects following treatment sessions as a means of understanding their reactions-whether, for example, they are actually experiencing treatment in the way the treater thinks they are experiencing it.

Many things might be done, but so long as the researcher prefers to examine variables traditionally defined as "objective," and leaves predictions based upon the treatment process to the subjective interpretations of the therapist, his behavior will by dysfunctional for the development of a scientific penology.

\section{Summary and Conclusion}

The foregoing analysis suggests that a successful bridging of the ideological gulf between researcher and treater might contribute significantly to the development of a scientific penology. It is recognized, of course, that efforts to eliminate this gulf in ongoing penal systems will not be simple. In those systems where punitive methods are still in practice, research poses as much a threat to those in control as it cloes to the clinician in treatment-centered systems. However, since the primary purpose of this paper has been to point out the dysfunctions which are perpetuated by the gulf, it would be hoped that future analyses could be devoted to defining, in detail, steps by which a new researchtreatment role might be implemented in both types of systems.

A summary of that which has been emphasized in this paper would seem to include two important points:

"Eugene L. Gaier, "When They're Not Talking," Adult Leadership, I, No. 10 (March, 1953), pp. 28-29; Eugene L. Gaier, "Memory Under Conditions of Stimulated Recall," The Journal of General Psychology, 50 (1954), pp. 147-153; B. S. Bloom, "The Thought Process of Students in Discussion," in Accent On Teaching, ed. by Sidney J. Flinch, Harper and Bros., 1954, Chap. 1.

\section{Research Model}

An effective analysis of any treatment system requires an integration of research and treatment efforts. At the very onset this would require a union of researcher and treater on theoretical matters. It would seem impossible to conduct effective evaluation unless the researcher participated intimately with the treater in defining goals in terms of a logical integration of causation theory, intervention strategy, and treatment roles. Therefore, cooperation between these two parties would permit the treater to enter into the problems associated with Stages I and III of the Research Model (the selection and comparison of treatment and control groups) and would permit entry of the researcher into problems associated with Stage II (the actual treatment process). The researcher could halp to operationalize treatment techniques and goals, and the treater could illustrate some of the complexities of the treatment process.

Statistical findings on the success or failure of any program (Stage III) could best be understood if data were available by which to establish whether the causation theory or the actual treatment techniques used (Stage II) were responsible for any differences that were found, or whether one must look to other variables impinging upon treatment for explanations. Such differences could be due to variables which are not a direct function of treatment. If this is the case they must be discovered.

\section{Communication and the Avoidance of Anxiety}

The second point in bridging the gulf between treater and researcher has to do with the importance of maintaining treater-researcher communication and responsibility regarding research findings.

The goal would be two-fold: (1) to approach current techniques with a disciplined skepticism-that is, any treatment technique would be riewed as an 
hypothesis to be examined rather than a method based upon absolute knowledge; and (2) to give both parties a greater stake in the development of new knowledge about treatment techniques rather than in the perpetuation of traditional vested interests.

A new and shared vested interest, based upon a desire for new knowledge, would help to reduce anxiety on the treater's part over any results which discredit his technique. Instead of threatening him with economic and prestige problems, as though his practices were of an all-ornone variety, he, along with the researcher, would be called upon to revise techniques or develop new ones.

This, of course, would not eliminate anxiety, only modify it. Now, however, both could be more concerned with the dimension of discovery; that is, with the problem of knowing what is really happening to inmates as a result of treatment practices rather than with the maintenance of power in the correctional structure. The latter type of anxiety could only be reduced by a scientific approach to the understanding and improvement of rehabilitative techniques.

The field of corrections is now at a stage where the humanitarian concern for the welfare of prisoners by professionals needs to be at least partially supplanted by a disciplined, scientific orientation. The alternatives open to society and those working with offenders are limited. What can be done with hard-core offenders except to: destroy them, incarcerate them permanently, or rehabilitate them? The tendency among most people has been toward the latter alternative. However, so long as the vested interests of research and treatment personnel continue to pursue divergent goals, it will be difficult to establish a scientific penology by which reliable answers can be discovered. On the other hand, the welding of research and treatment roles might constitute one step towards a comprehensive understanding of, and fruitful approach to, the problems involved.

The exclusive focus on the field of corrections in this paper is a function of the author's experience in that area. I suspect, however, that the problems described above occur in such diversified fields as education, social work, administration and governmental planning. The prerequisites of organizational maintenance seem to necessitate these conflicts and problems. The solution would seem to be not only to call for the development of closer, working relationships, but to institutionalize the training and organization of individuals who can work effectively within both organizational contexts. 